\title{
Rapid spread of a SARS-CoV-2 Delta variant with a frameshift deletion in ORF7a
}

\author{
Dr. Charles S.P. Foster, PhD'; Prof. William D. Rawlinson MBBS, $\mathrm{PhD}^{2}$ \\ ${ }^{1}$ School of Medical Sciences, University of New South Wales Sydney, Sydney, NSW, Australia \\ ${ }^{2}$ Serology and Virology Division, NSW Health Pathology, Prince of Wales Hospital, Sydney, NSW, Australia
}

\begin{abstract}
Australia is currently experiencing COVID-19 outbreaks from infection with SARS-CoV-2 Delta variants (B.1.617.2, AY.3). Analysis of the index case reveals a sub-consensus level of sequencing reads $(\sim 25 \%)$ that support a 17 -nucleotide deletion in ORF7a (ORF7a $\left.{ }^{\Delta 17 d e l}\right)$. ORF7a $a^{\Delta 17 d e l}$ induces a frameshift mutation in ORF7a, which truncates the peptide and potentially leads to reduced suppression of host restriction factor BST-2/CD317/Tetherin. Despite this, the mutation has rapidly become represented at the consensus level in subsequent cases: approximately $72 \%$ of SARSCoV-2 genomes in the Australian outbreak possess ORF7a ${ }^{\Delta 17 d e l}$, and $99.7 \%(1534 / 1538)$ of Delta genomes on GISAID with ORF7a ${ }^{\Delta 17 d e l}$ originate from the current Australian outbreak (5 August 2021). The global abundance of this mutation might be underestimated given the difficulty of variant calling software correctly calling insertion/deletions (indels), the common inability of phylogenetics software to take indels into account, and the tendency of GISAID to not release submissions that contain a frameshift mutation (unless specifically requested). Overall, the rapid increase of persistent ORF7a ${ }^{\Delta 17 d e l}$ variants is concerning, and suggests either a chance founder effect with a neutral mutation yet to be purged, or that the ORF7a ${ }^{\Delta 17 d e l}$ mutation provides a direct selective advantage.
\end{abstract}

\section{Main text}

SARS-CoV-2 encodes proteins that modulate antiviral responses (ORF3b, ORF6, ORF7a), including reducing type 1 interferon ${ }^{1}$. The ORF7a of SARS-CoV-2 is an ortholog of the corresponding SARS-CoV antagonist of host restriction factor BST-2/CD317/Tetherin that induces apoptosis ${ }^{2,3}$. Cells with reduced BST2 enhance SARS-CoV-2 replication thereby releasing more virus $^{3}$. Deletion mutations at the SARS-CoV-2 C-terminus of ORF7a are frequent. An 81-nucleotide in-frame deletion in ORF7a removes signal peptide and beta strand sequences, which was detected in March $2020^{2}$. However, ORF7a deletions are generally transient. This may be due to reduced viral fitness, possibly as a consequence of reduced suppression of host innate immunity ${ }^{1}$.

Australia is currently experiencing COVID-19 outbreaks (>5000 cases) from infection with SARSCoV-2 Delta variants (B.1.617.2, AY.3). These are characterised by increased frequency of

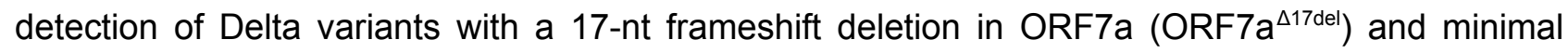
other changes in the gene. This deletion spans genome positions $27607-27623$ and leads to a truncated (78 vs 121 amino acids) peptide (Fig. 1A,B). The first virus of the current outbreak was collected on June 16, and the consensus genome exhibited a $100 \%$ match to a USA sequence with complete ORF7a (lacking ORF7a ${ }^{\Delta 17 \mathrm{del}}$ ) that was the likely progenitor (Fig. 1A). Notably, the index case of current Australian COVID-19 outbreaks and close contacts possessed a subconsensus fraction of sequencing reads $(\sim 25 \%)$ with $O R F 7 a^{\Delta 17 d e l}$. We sequenced the first Delta genome with consensus-level ORF7a $\mathrm{a}^{\Delta 17 \mathrm{del}}$ in Australia on June 18 , and $\sim 72 \%$ of SARS-CoV-2 genomes in the Australian outbreak possess ORF7a ${ }^{\Delta 17 \mathrm{del}}$ (Fig. 1C). This is likely an underestimate as it includes returned travellers and incomplete genome sequences. Analysis of 392,734 wholegenome SARS-CoV-2 Delta variant sequences from GISAID (5 August 2021) showed 99.7\% (1534/1538) originate from the current Australian outbreak. 
medRxiv preprint doi: https://doi.org/10.1101/2021.08.18.21262089; this version posted August 21, 2021. The copyright holder for this preprint (which was not certified by peer review) is the author/funder, who has granted medRxiv a license to display the preprint in It is made available under a CC-BY-NC-ND 4.0 International license .

The occurrence of ORF7a deletions in viruses from multiple countries throughout the pandemic suggests many deletions do not impair fitness, although gene truncation is generally associated with production of proteins with different or no activity. If ORF7a reduces BST2 effects in coronaviruses and BST2 knockdown enhances virion production ${ }^{4}$, the persistence of ORF7a ${ }^{\Delta 17 d e l}$ suggests it arose by either a chance founder effect or provides a direct selective advantage compensating for loss of BST2 suppression. The latter should be investigated with functional studies of viruses containing ORF7a ${ }^{\Delta 17 \mathrm{del}}$, such as replicon and in vitro organoid research into phenotypic change, as done with S-protein mutations ${ }^{5}$. Given the many Delta variant COVID19 cases worldwide, the possible global spread of ORF $7 a^{\Delta 17 d e l}$ should be closely monitored.

\section{References}

1. Nemudryi A, Nemudraia A, Wiegand T, et al. SARS-CoV-2 genomic surveillance identifies naturally occurring truncation of ORF7a that limits immune suppression. Cell Rep 2021;35(9):109197.

2. Holland LA, Kaelin EA, Maqsood R, et al. An 81-Nucleotide Deletion in SARS-CoV-2 ORF7a Identified from Sentinel Surveillance in Arizona (January to March 2020). Journal of Virology 94(14):e00711-20.

3. Martin-Sancho L, Lewinski MK, Pache L, et al. Functional landscape of SARS-CoV-2 cellular restriction. Molecular Cell 2021;81(12):2656-2668.e8.

4. Wang S-M, Huang K-J, Wang C-T. BST2/CD317 counteracts human coronavirus 229E productive infection by tethering virions at the cell surface. Virology 2014;449:287-96.

5. Saito A, Irie T, Suzuki R, et al. SARS-CoV-2 spike P681R mutation, a hallmark of the Delta variant, enhances viral fusogenicity and pathogenicity. bioRxiv 2021;2021.06.17.448820. 
medRxiv preprint doi: $h t t p s: / / d o i . o r g / 10.1101 / 2021.08 .18 .21262089$; this version posted August 21, 2021. The copyright holder for this preprint (which was not certified by peer review) is the author/funder, who has granted medRxiv a license to display the preprint in It is made available under a CC-BY-NC-ND 4.0 International license.
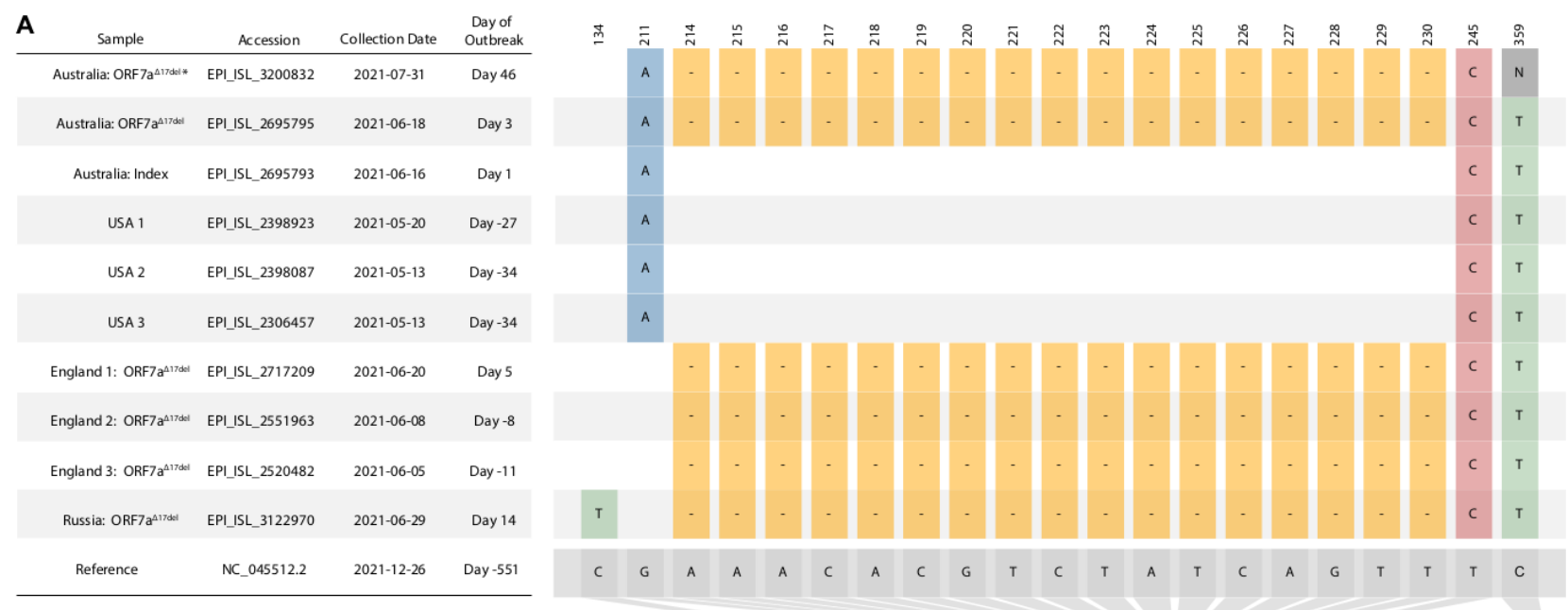

* Pango lineage for sample is AY. 3

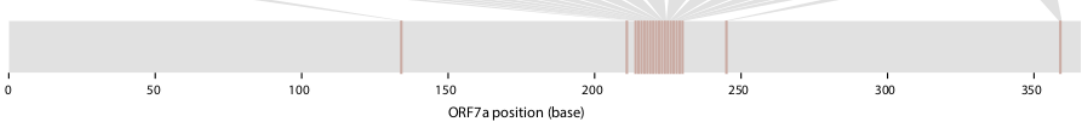

B

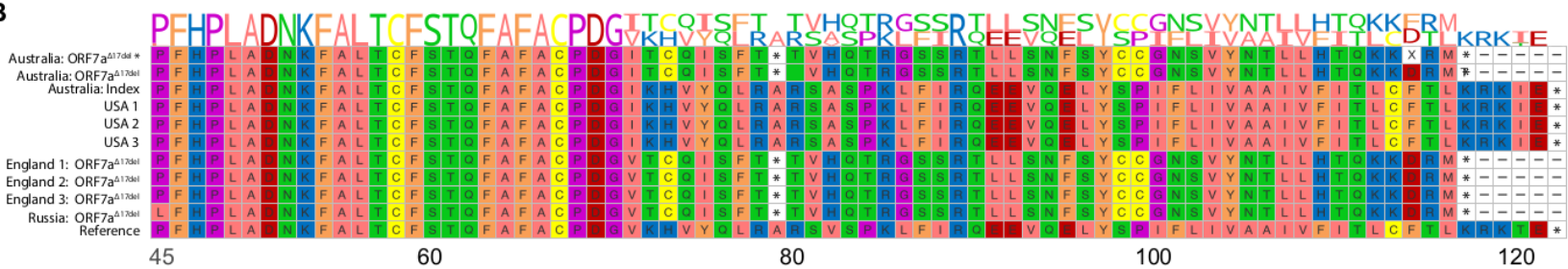

C

NSW

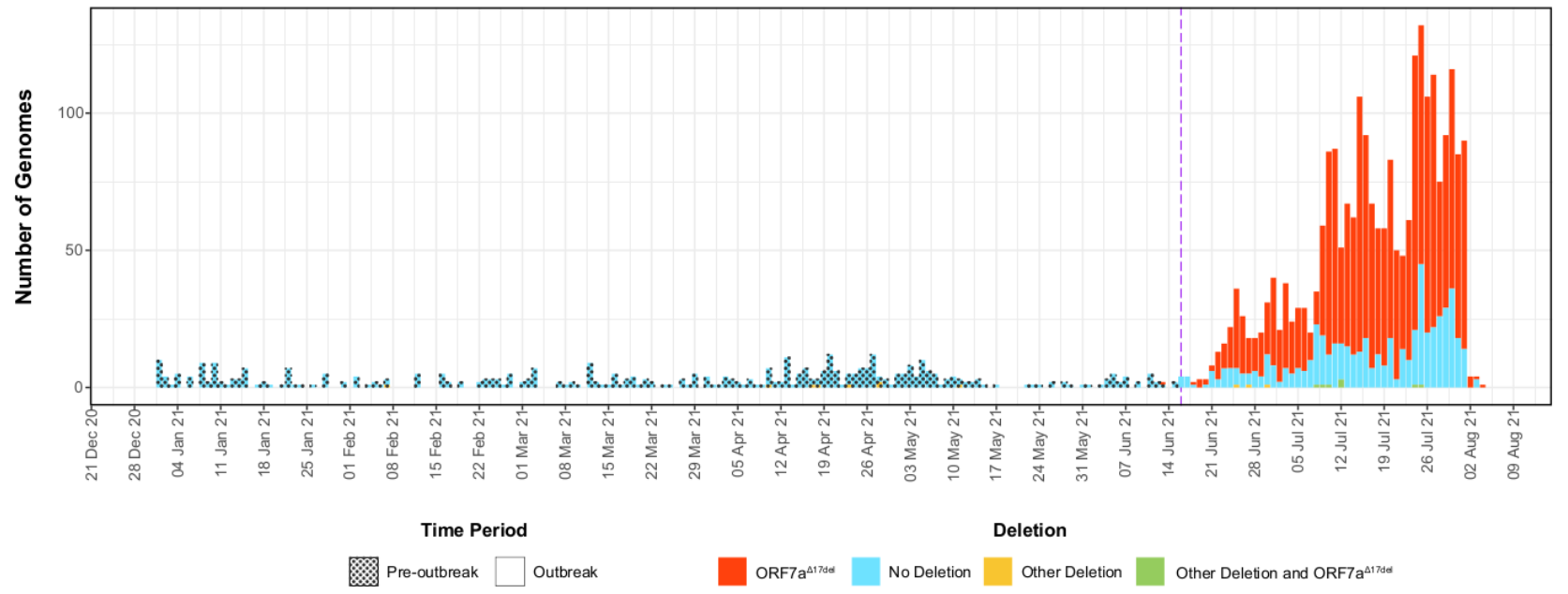

Figure 1. Visualisation of a 17-nucleotide deletion in ORF7a of Delta variant SARS-CoV-2 sequences (ORF7a ${ }^{\Delta 17 \mathrm{del})}$ from Australia, 2021, the possible functional consequences at the peptide level, and the increasing frequency in NSW, Australia. Sequences chosen for visualisation include the index case of the current outbreaks (lacking ORF7a ${ }^{\Delta 17 \mathrm{del}}$ ), the first Australian case possessing ORF7a ${ }^{\Delta 17 \mathrm{del}}$, the only sample

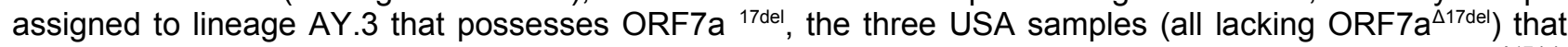
match the Australian index case, and the only four non-Australian samples to possess ORF7a ${ }^{\Delta 17 d e l}$. Accession numbers for all samples analysed for this panel are in the Supplementary Appendix, available with the full text of this letter online. Panel A shows the sample dates of all chosen samples relative to the index case of the current outbreaks (16 June 2021), and all variants in the sample genomes relative to the SARSCoV-2 reference genome (created in part using snipit (https://github.com/aineniamh/snipit). Panel B illustrates the consequences of ORF7a ${ }^{\Delta 17 \mathrm{del}}$ on the amino acid translation of ORF7a, leading to a premature stop codon after amino acid 78 and a truncated peptide sequence ( $64 \%$ complete). Amino acids $1-44$ are identical to the SARS-CoV-2 reference genome in all samples and are not presented. Panel C demonstrates the number of genomes of all lineages from Australia from 01 January 2021 until 11 August 2021 with ORF7a $a^{\Delta 17 \mathrm{del}}$, ORF7a ${ }^{\Delta 17 \mathrm{del}}$ plus other deletion(s), other deletions in ORF7a only, or no deletions in ORF7a. The purple dashed line indicates the beginning of the current outbreaks in Australia, with shading also indicating pre-outbreak and outbreak samples. 


\section{A}

Day of

Dutbreak

Australia: ORF7a ${ }^{\text {17ddel * }} \quad$ EPI_ISL_3200832 2021-07-31 Day 46

Australia: ORF7a ${ }^{\Delta 17 d e l} \quad$ EPI_ISL_2695795 2021-06-18 Day 3

Australia: Index EPI_ISL_2695793 2021-06-16 Day 1

USA 1 EPI_ISL_2398923 2021-05-20 Day -27

USA 2 EPI_ISL_2398087 2021-05-13 Day-34

USA 3 EPI_ISL_2306457 2021-05-13 Day-34

medRxiv preprint doi: https://doi.org/10.1101/2021.08.18.21262089; this version posted August 21, 2021. The copyright holder for this

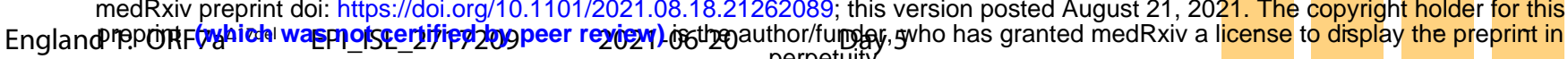
It is made available under a CC-BY-NC-ND 4.0 International license. England 2: ORF7a ${ }^{\triangle 17 d e l} \quad$ EPI_ISL_2551963 2021-06-08 Day -8 England 3: ORF7a ${ }^{\Delta 17 d e l} \quad$ EPI_ISL_2520482 2021-06-05 Day-11 Russia: ORF7a ${ }^{\Delta 17 d e l} \quad$ EPI_ISL_3122970 2021-06-29 Day 14

Reference NC_045512.2 2021-12-26 Day -551

* Pango lineage for sample is AY. 3

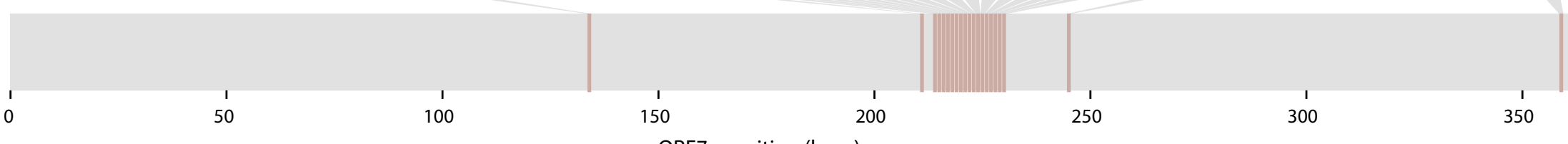

B

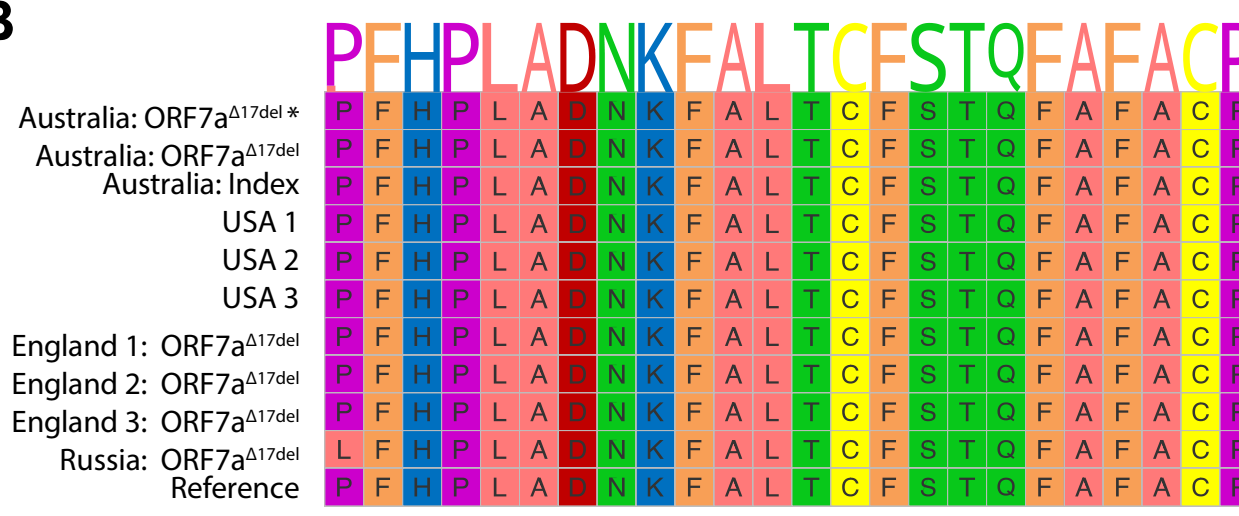

45

60

80

ORF7a position (base)

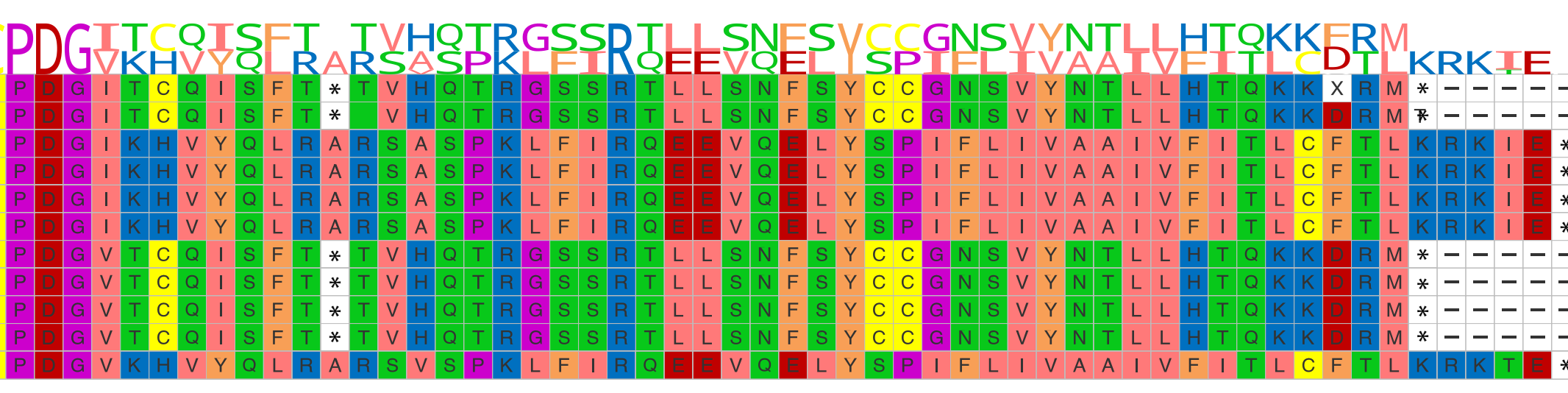

C

NSW

¿

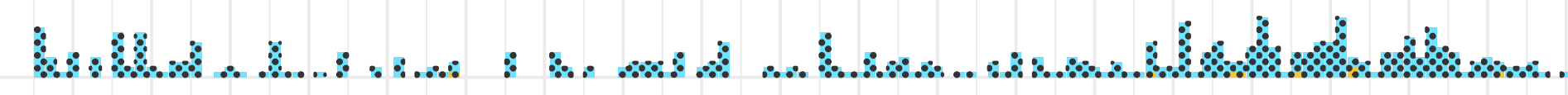

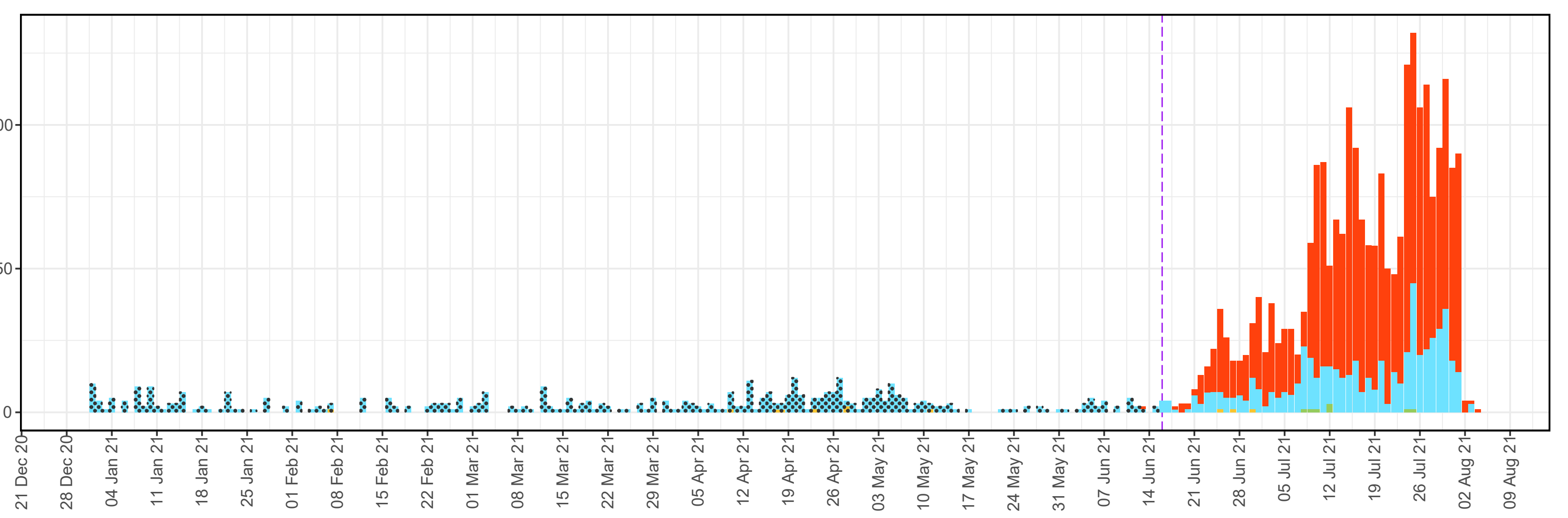

Time Period

Deletion

Pre-outbreak $\square$ Outbreak

ORF7a $a^{\Delta 17 d e l} \quad$ No Deletion $\quad$ Other Deletion

Other Deletion and ORF7a ${ }^{\Delta 17 d e l}$ 